\title{
Japanese loanword devoicing revisited: A rating study
}

\author{
Shigeto Kawahara \\ Rutgers University \\ kawahara@rci.rutgers.edu
}

\begin{abstract}
In Japanese loanword phonology, geminates optionally devoice when there is another voiced obstruent within the same stem, i.e., geminates may optionally devoice when they violate $\mathrm{OCP}$ (voice). This devoicing of $\mathrm{OCP}$-violating geminates has received much attention in the recent phonological literature. However, the debates centering around this phenomenon have relied primarily on intuition-based data, and no systematic wellformedness judgment experiments have been performed. This paper fills that gap. The experiment reported in this paper shows that Japanese speakers do find devoicing of geminates natural when there is another voiced stop within the same word, i.e., when the geminates violate OCP(voice). The experiment moreover finds other interesting aspects of devoicing: (i) the naturalness of devoicing of OCP-violating geminates correlates positively with the lexical frequencies of the words in question, (ii) the naturalness of devoicing of OCP-violating geminates is not significantly affected by place of articulation, (iii) speakers find (context-free) devoicing of geminates more natural than devoicing of OCP-violating singletons, and (iv) speakers find the devoicing of OCP-violating singletons more natural in word-medial position than in word-initial position.
\end{abstract}

\section{Introduction}

\subsection{The phenomena}

This paper reports a wellformedness judgment experiment on the devoicing of voiced geminates in Japanese loanword phonology, a topic that has received much attention in the recent phonological literature. Japanese native phonology does not permit voiced geminates (Itô \& Mester, 1995, 1999), but gemination in recent loanwords has brought about voiced geminates in Japanese loanword phonology (e.g. [eggu] 'egg' and [doggu] 'dog'). Itô and Mester (1999) observe that some 
such geminates are devoiceable whereas others are not; to account for this difference, they treat devoiceable geminates as contained in assimilated foreign items and non-devoiceable geminates as contained in unassimilated foreign items.

Instead of relying on an etymological distinction, Nishimura (2003) has identified a phonological condition which makes devoicing of geminates possible: the presence of another voiced obstruent. Nishimura argues that $\mathrm{OCP}(\text { voice })_{\text {stem }}$, which prohibits two voiced obstruents within the same stem, is the key to coercing the devoicing of geminates-compare (1) and (2). This argument by Nishimura is attractive since we know independently that $\mathrm{OCP}($ voice) is active in native Japanese phonology (Itô \& Mester, 1986). ${ }^{1}$ One complication, however, is that singletons do not seem to undergo devoicing even when they violate $\mathrm{OCP}($ voice $)$-compare (1) and (3).

(1) Geminates can optionally devoice if they co-occur with another voiced obstruent ${ }^{2}$
a. baddo $\rightarrow$ batto 'bad'
b. baggu $\rightarrow$ bakku 'bag'
c. $\operatorname{doggu} \rightarrow$ dokku 'dog'

(2) Geminates do not devoice otherwise
a. sunobbu $\rightarrow$ *sunoppu 'snob'
b. reddo $\rightarrow$ *retto 'red'
c. eggu $\rightarrow$ *ekku 'egg'

(3) Singletons do not devoice even when they violate $\mathrm{OCP}($ voice)
a. gibu $\rightarrow$ *gipu 'give'
b. bagu $\rightarrow$ *baku 'bug'
c. dagu $\rightarrow *$ daku 'Doug'

Since Nishimura (2003) identified the patterns in (1)-(3), they have received much attention in the literature (Coetzee \& Pater, to appear; Crawford, 2009; Farris-Trimble, 2008; Haraguchi, 2006; Hayes, 2009; Itô \& Mester, 2008; Kaneko \& Iverson, 2009; Kawahara, 2006, 2008; McCarthy, 2008; Pater, 2009; Pycha et al., 2006; Rice, 2006; Steriade, 2004; Tanaka, 2010; Tateishi, 2002; Tesar, 2007). One debate focuses on the difference between singletons and geminateswhy do Japanese speakers devoice only geminates under the influence of OCP(voice) (Kawahara,

\footnotetext{
${ }^{1}$ OCP(voice) in Japanese is also known as Lyman's Law (Lyman, 1894). Native Japanese phonology generally does not allow stems with two voiced obstruents. OCP(voice) also blocks Rendaku, voicing of the initial consonant of the second member of a compound, when the second member already contains a voiced obstruent (Itô \& Mester, 1986; Vance, 1980). OCP(voice) in Japanese targets voicing only in obstruents, but not in sonorants (Itô \& Mester, 1986; Mester \& Itô, 1989). See Vance (1980) for an experiment on OCP-induced blockage of Rendaku.

${ }^{2}$ An anonymous reviewer pointed out that in some cases these OCP-violating geminates are spelled as voiceless; e.g. gutto laihu kanpanii ‘Good life company' (http://gootlife.com) and gutto hikkoshi sentaa 'Good moving company' (http://a-hikkoshi.com/cooperation/good.html); a google search also reveals that Buddha is often spelled as butta.
} 
2006, 2008; Rice, 2006; Steriade, 2004)? In answer to this question Kawahara (2006; 2008), for example, has demonstrated that Japanese voiced geminates are phonetically semi-devoiced and that a voicing contrast is therefore perceptually harder to hear in geminates than in singletons; these experimental results arguably show that phonetic perceptibility plays a role in determining phonological neutralizability (Steriade, 2001/2008).

Another set of work focuses on the seemingly cumulative behavior of devoicing: neither geminacy nor OCP(voice) alone can coerce devoicing (see (2) and (3)); only when both of the factors are relevant, does devoicing become possible (Coetzee \& Pater, to appear; Farris-Trimble, 2008; Hayes, 2009; Pater, 2009; Tesar, 2007). This cumulative behavior may bear on a general theory of constraint interaction. Such a behavior is impossible to model in a strict ranking-based theory of constraint interaction, such as Optimality Theory (Prince \& Smolensky, 1993/2004), unless there is a constraint that is violated only when both $\mathrm{OCP}$ (voice) and a constraint against voiced geminates are violated (Nishimura, 2003), or unless we posit different faithfulness constraints for singletons and geminates (Kawahara, 2006, 2008). However, a theory with weighted, rather than ranked, constraints can model the cumulative pattern without positing a complex markedness constraint or differentiated faithfulness constraints (Pater, 2009).

Finally, yet another set of work addresses why and how the patterns in (1)-(3) spontaneously emerged in loanword phonology, especially given that native phonology does not allow voiced geminates or OCP-violating singletons. One particular question is the one discussed above: where does the difference between singletons and geminates stem from? Some other work moreover addresses how the emergence of the devoicing of OCP-violating geminates bears on a general theory of loanword adaptation and lexical stratification: the fact that $\mathrm{OCP}$ (voice), which is active in native Japanese phonology, plays a role in loanword phonology may shed light on how loanword phonology is related to native phonology (Crawford, 2009; Itô \& Mester, 2008; Tateishi, 2002).

In summary, the patterns in (1)-(3) have evoked many theoretical debates. This paper does not attempt to model the intricate patterns of devoicing or resolve the issues that are raised in the literature cited above; interested readers are referred to those works. Rather, the current concern is instead that the data in (1)-(3) is largely based on native authors' intuitions by Nishimura (2003) and Kawahara (2006). Although Nishimura (2003) and Kawahara (2006) back up their intuitions using corpus search and informal native speaker consultation, systematic judgment studies of OCPviolating geminates have not been conducted.

\subsection{The need for experimentation}

The aim of this paper, therefore, is to validate the generalizations exemplified in (1)-(3), since several important theoretical claims have been made using these patterns. This study is inspired and motivated by an increasing interest in testing the quality of linguistic data using experimental 
methodology (Berko 1958; Cowart 1997; Dabrowska 2010; Hayes \& Londe 2006; Kawahara 2011; Myers 2009; Nolan 1992; Schütze 1996, among others). Here I briefly summarize why experimentation is necessary beyond intuition-based data collection (see the work cited and references cited therein for more general and elaborate discussion of the following points).

The first general concern is that some phonological patterns that are used to argue for particular theoretical claims have been shown to be unproductive or non-reproducible in experimental settings (e.g. Alderete \& Kochetov 2009; Batchelder 1999; Griner 2001; Jaeger 1983; Ohala 1974; Sanders 2003; Vance 1987). One example is Japanese verbal conjugation patterns; several experiments show that native Japanese speakers do not reproduce alleged phonological alternations in verb conjugations (Batchelder, 1999; Griner, 2001; Vance, 1987). (See Davis and Tsujimura 1991 for a review of alternations in Japanese verbal conjugations and an autosegmental analysis.) More recently, Alderete and Kochetov (2009) show that a case of conflicting directionality of a palatalization feature in Japanese mimetics (Hamano, 1986; Mester \& Itô, 1989) is not productively reproduced by native speakers. These examples highlight the importance of systematic experimentation in order to guarantee the productivity of the phonological patterns under question; otherwise we may run the risk of building a theory based on unproductive linguistic patterns.

The second concern is that of generalizability. When the data are based on the intuition of two authors, we cannot guarantee that their intuitions generalize to the whole population of Japanese speakers. In order to assure that the patterns in (1)-(3) are a general property of Japanese phonology, rather than the phonology of two specific individuals, it is necessary to gather data from a large number of speakers. The third concern is replicability: in an intuition-based approach, we cannot guarantee the replicability of the results, because the procedure of obtaining the intuition-based data is "private", relying on the inner sensation of informants, who are, in the case of Nishimura (2003) and Kawahara (2006) (and often in other cases as well), the authors themselves (see Schütze 1996: 48-52). Because of this problem, we do not have a measure to evaluate the replicability of an informal judgment, unless we follow a rigorous experimental protocol.

The fourth concern of the intuition-based approach is bias (Dabrowska, 2010; Gibson \& Fedorenko, 2010): authors can be biased due to their theoretical commitments. The purely intuitionbased approach runs the risk of (unconsciously) skewing and/or oversimplifying the actual data in the process of introspection. To avoid this problem, it would be ideal to obtain data from naive speakers. The final concern is that judgments are often made in terms of a binary, grammatical/ungrammatical choice, as is the case in Nishimura (2003) and Kawahara (2006). However, it is known that grammaticality judgement experiments can reveal more nuanced distinctions among "grammatical" forms or among "ungrammatical forms" (see e.g. Cohn 2006; Cowart 1997; Greenberg \& Jenkins 1964; Hayes 2000, 2009; Myers 2009; Pertz \& Bever 1975; Pierrehumbert 2001). For these reasons, experimental testing of linguistic data should complement—if not replace- 
intuition-based data.

\subsection{Additional hypotheses tested}

These considerations call for verification of the empirical foundations of linguistic theory, beyond an intuition-based approach to linguistics. To that end, I conducted a wellformedness judgment experiment that tests the validity of the generalizations stated in (1)-(3). In addition, the experiment was designed to address some particular additional aspects of devoicing in (1).

One additional hypothesis that is tested is an informal observation, or an intuition, that Japanese speakers sometimes have about the devoicing of geminates - the more frequent the words are, the more natural it is to devoice OCP-violating geminates. This intuition was shared by native Japanese speakers that I consulted, but has never been substantiated by a systematic study. The effects of lexical frequencies on phonological patterns have been receiving an increasing interest in recent phonological and psycholinguistic studies (see e.g. Bybee 1999, 2001; Coleman \& Pierrehumbert 1997; Ernestus \& Baayen 2003; Frisch et al. 2000; Hay et al. 2003; Hayes 2009; Hayes \& Londe 2006; Zuraw 2009). For example, in Usage-based Phonology (Bybee, 1999, 2001), frequency is one major factor that governs and shapes phonological regularity (see also Coleman \& Pierrehumbert 1997; Frisch et al. 2000; Hay et al. 2003). Therefore it is important to investigate the extent to which frequency can affect the devoicing of OCP-violating geminates.

Another aspect of the devoicing pattern that is tested in the following experiment is the place effect: According to Nishimura's (2003) data, [gg] is more likely to be devoiced than [dd] (Kawahara, 2006), and in relation to this observation, Kawahara (2006) shows that a voicing contrast is less perceptible in [gg] than in [dd]. Kawahara (2006) takes this correlation as additional evidence that the perceptibility of a phonological contrast correlates with the neutralizability of that contrast. A question thus remains as to whether Japanese speakers would indeed show a difference in the devoiceability of OCP-violating geminates based on their place of articulation.

\subsection{Why a wellformedness judgment task?}

To test these hypotheses, the current study conducted a wellformedness judgment experiment. Some remarks on why a wellformedness judgment task was specifically chosen are now in order. First, wellformedness judgment tasks with a numerical response scale are known to reveal subtle distinctions of grammaticality beyond the grammatical/ungrammatical dichotomy (see the references above at the end of section 1.2). Second, testing the intuitive correlation between the frequencies of lexical items and the likelihood of devoicing requires us to obtain quantitative measures of grammaticality, comparable to the frequencies of the items under question. In summary, in a wellformedness study with a larger number of speakers in which we control for the relevant 
variables, we can gain further insight into the phenomenon.

\subsection{A preview of the results}

The experiment reported below shows that Japanese speakers do find the devoicing of geminates natural when the geminates violate $\mathrm{OCP}$ (voice), supporting the basic intuitions of Nishimura (2003) and Kawahara (2006). Therefore it succeeds in securing the empirical foundations of the theoretical claims reviewed above in section 1.1. However, the experiment reveals other interesting systematic patterns as well: (i) the naturalness ratings of devoicing of OCP-violating geminates positively correlates with the lexical frequencies of the words in question, (ii) the naturalness ratings of the devoicing of voiced geminates are not significantly affected by place of articulation, (iii) speakers find the (context-free) devoicing of geminates more natural than the devoicing of OCP-violating singletons, and (iv) speakers find the devoicing of OCP-violating singletons more natural in word-medial position than in word-initial position.

\subsection{One caveat}

Before moving onto the description of the experiment, it needs to be made clear that the patterns in (1)-(3) are a part of loanword phonology rather than the process of loanword adaptation per se. In other words, we are interested in how Japanese speakers treat words that they have already borrowed and adapted from other languages (for studies of Japanese loanword adaptation, see Lovins 1973; Kaneko \& Iverson 2009; Katayama 1998; Shinohara 2004). On this note, Kaneko and Iverson (2009) conducted a production adaptation study on how Japanese speakers adapt (mostly) nonce English words, and did not find evidence for devoicing of OCP-violating geminates in the process of adaptation. Therefore, if devoicing in (1) happens at all, then it is in the loanword phonology of already-borrowed forms rather than in loanword adaptation.

\section{Method}

In this experiment, Japanese speakers judged the naturalness of the devoicing of singletons and geminates in various contexts.

\subsection{Stimuli}

This experiment used real words for two reasons: (i) in order to test the data of Nishimura (2003) and Kawahara (2006) and (ii) to test the effect of lexical frequencies on the naturalness of devoicing. Therefore, the stimuli were taken from the lists of items provided in Kawahara (2006), which 
itself builds on Nishimura (2003). The design had three conditions: (i) OCP-violating geminates as in (1), (ii) non-OCP-violating geminates as in (2), and (iii) OCP-violating singletons as in (3). Words with only one singleton were not included among the stimuli, because neither Nishimura (2003) nor Kawahara (2006) discuss them. ${ }^{3}$ The complete list of the stimuli is provided in Table 1. There is only one word that contains OCP-violating [bb]. The scarcity of this sort of form is due to the fact that in loanword adaptation, [b] tends to resist gemination compared to [d] and [g] (Kaneko \& Iverson, 2009; Katayama, 1998; Shirai, 2002).

Table 1: The list of stimuli. Based on Kawahara (2006)

\begin{tabular}{llllll}
\multicolumn{2}{l}{ OCP-violating geminates } & Non-OCP-violating geminates & \multicolumn{2}{l}{ OCP-violating singletons } \\
\hline gebberusu & 'Göbbels' & webbu & 'web' & bagii & 'buggy car' \\
guddo & 'good' & sunobbu & 'snob' & bobu & 'Bob' \\
beddo & 'bed' & habburu & 'Hubble' & dagu & 'Doug' \\
doreddo & 'dread' & kiddo & 'kid' & daiyamondo & 'diamond' \\
deddobooru & 'deadball' & reddo & 'red' & giga & 'giga' \\
baddo & 'bad' & heddo & 'head' & gibu & 'give' \\
deibiddo & 'David' & suraggaa & 'slugger' & bogii & 'bogey' \\
budda & 'Buddha' & eggu & 'egg' & bagu & 'bug' \\
doggu & 'dog' & furaggu & 'flag' & daibu & 'dive' \\
baggu & 'bag' & & & doguma & 'dogma' \\
doraggu & 'drag' & & & gaburieru & 'Gabriel' \\
biggu & 'big' & & & gaidansu & 'guidance'
\end{tabular}

\subsection{Task}

The task was a wellformedness judgment task. In the general instructions, the participants were told that the questionnaire was about the naturalness of devoicing (i.e. that the experiment was about "daku-on" (voiced obstruents)). They were also told that the experiment is about loanwords. For each question, the participants were first presented with one word from the stimulus list, and they were asked to judge the naturalness of the form that undergoes devoicing (e.g. given [gebberusu], how natural would you find it to pronounce it as [gepperusu]?). They were asked to provide their judgments on a 5-point scale: A. "very natural", B. "somewhat natural", C. "neither natural nor unnatural", D. "somewhat unnatural", and E. "very unnatural". ${ }^{4}$ They were then asked to read the stimuli before answering each question, and to base their decision on their auditory impression rather than on orthography. For the stimuli containing OCP-violating singletons (the

\footnotetext{
${ }^{3}$ For the effect of OCP(voice) on singletons, see Kawahara (2010).

${ }^{4}$ The software used to present the stimuli (see below) did not allow us to present the scale numerically, so numeric conversion was applied later.
} 
rightmost column in Table 1), they were asked to judge the naturalness of both devoicing of wordinitial singletons and word-internal singletons. These two questions were presented separately.

\subsection{Procedure}

The test was administered through Sakai (https://sakai.rutgers.edu/portal), a Java-based system that runs online experiments (see Reips 2002 for general discussion of web-based experimentation). The first page of the experimental website showed a consent form for a human subject experiment. Once the participants agreed to participate in the experiment, they were forwarded to a testing site. On each page, Sakai presented one stimulus, and asked how natural the devoiced form of that stimulus was on the 5-point scale described above. The instructions and the options were provided in Japanese orthography; the stimuli and the forms undergoing devoicing were presented in katakana orthography, which is used for loanwords; the instruction sentences and the options were provided in a mixture of kanji and hiragana, following the standard Japanese orthographic convention. The order of the stimuli was randomized by Sakai. At the end of the experiment, they were asked if they were familiar with the devoicing phenomenon of OCP-violating geminates; those who answered positively to this question were excluded from the following analysis.

\subsection{Participants}

38 native speakers of Japanese completed the study. Two speakers were however familiar with the devoicing phenomenon, and therefore were excluded from the following analysis.

\subsection{Frequency measures}

The frequencies of the items were counted based on a Japanese lexical corpus, Amano and Kondo (2000). ${ }^{5}$ The mean log-frequencies of the three conditions were comparable (OCP-violating geminates: 4.57, non-OCP-violating geminates: 4.32, OCP-violating singletons: 4.48).

\subsection{Statistics}

The responses were first converted to numerical values as follows: "very natural"=5; "natural"=4; "neither natural nor unnatural"=3; "unnatural"=2; "very unnatural"=1. For statistical analyses, first, a general linear mixed model was run (Baayen et al., 2008; Baayen, 2008; Bates, 2005) using R (R Development Core Team, 1993-2010) with the lme 4 package (Bates \& Sarkar, 2007).

\footnotetext{
${ }^{5}$ An alternative would be to use frequencies on the internet using search engines such as Google. A problem with this approach is that since Japanese orthography does not insert a space between words, a search for a word automatically includes words that contain the target word; e.g. if we search for the word $\operatorname{dog} u$ ' dog', the results will for example include hotto doggu 'hot dog'.
} 
Rating scores were regressed against a model in which OCP, geminacy, place and frequency were fixed factors and speakers and items were random factors. Since OCP and geminacy were not fully-crossed (there were no non-OCP-violating singletons), the interaction term between them was not coded, although the cumulative effect of OCP and geminacy would show up in their interaction term. Instead this general analysis was followed by specific contrast analyses. The $\operatorname{lm} 4$ e package does not automatically compute $\mathrm{p}$-values because the exact procedure to calculate degrees of freedom has not been discovered. Therefore, the p-values, as well as the $95 \%$ confidence intervals of the coefficients of the fixed factors, were calculated by the Markov chain Monte Carlo method using the pval. fnc () function of the languageR package (Baayen, 2009). Finally, the correlations between the naturalness ratings and the lexical frequencies were checked using a Spearman correlation test, again using $\mathrm{R}$.

\section{Results}

\subsection{General results}

Figure 1 plots the averages of the naturalness rating of devoicing in the four conditions: OCPviolating geminates (e.g. /guddo/ $\rightarrow$ [gutto]); non-OCP-violating geminates (e.g. /heddo/ $\rightarrow$ [hetto]); OCP-violating singletons (initial) (e.g. /bagu/ $\rightarrow$ [pagu]); OCP-violating singletons (noninitial) (e.g. /bagu/ $\rightarrow[$ baku]). The y-axis represents the naturalness ratings in the following way: 5="very natural", 4="somewhat natural", 3="neither natural nor unnatural", 2="somewhat unnatural", $1=$ "very unnatural". The error bars represent $95 \%$ confidence intervals based on the variability across all relevant items and speakers and a $t$-distribution.

Japanese speakers find the devoicing of OCP-violating geminates most natural (the average is 3.89, around "somewhat natural"). Japanese speakers also find the devoicing of non-OCP-violating geminates more natural (the average is 2.40 , somewhere between "neither natural nor unnatural" and "somewhat unnatural") than the devoicing of OCP-violating singletons; they also find the devoicing of singletons more natural in medial position (the average is 1.75 , near "somewhat unnatural") than in initial position (the average is 1.42, somewhere between "somewhat unnatural" and "very unnatural").

A general linear mixed model showed that geminacy, OCP, place and frequency all affect naturalness rating (geminacy: $t=40.5, p<.001$; OCP: $t=19.58, p<.001$; place: $t=2.78, p<.01$; frequency: $t=4.68, p<.001$ ). A contrast analysis comparing OCP-violating geminates (the first bar in Figure 1) and non-OCP-violating geminates (the second bar) turned out to be significant $(t=19.3, p<.001)$. We also observe a difference between non-OCP-violating geminates (the second bar) and non-initial OCP-violating singletons (the fourth bar) $(t=22.02, p<.001)$. 


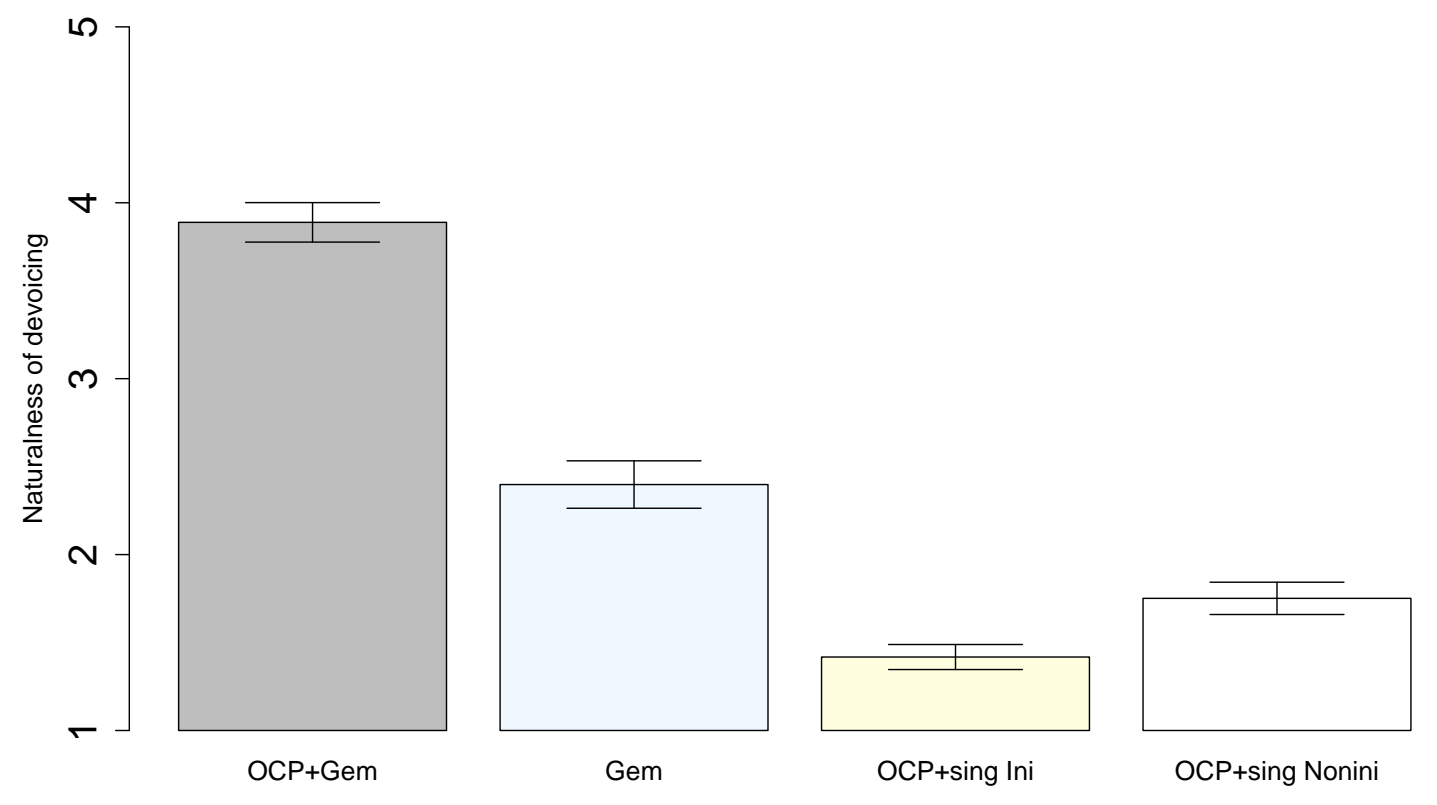

Figure 1: The averages of the naturalness rating in four conditions: OCP-violating geminates; non-OCP-violating geminates; OCP-violating singletons (initial); OCP-violating singletons (noninitial). The error bars represent $95 \%$ confidence intervals, calculated based on variability over each response and a t-distribution. 
(Geminates in Japanese appear only non-initially, and hence this comparison controls for position within words.) Third, speakers found the devoicing of non-initial singletons more natural than the devoicing of initial singletons (the third bar vs. the fourth bar: $t=-6.65, p<.001$ ). Table 2 lists the $95 \%$ confidence intervals calculated by the Markov chain Monte Carlo method for all these fixed effect coefficients. None of the intervals overlap with 0 .

Table 2: The $95 \%$ confidence intervals of the coefficients of the linear mixed models. Contrast $\mathrm{I}=\mathrm{OCP}$-violating geminates vs. non-OCP-violating geminates; Contrast II=Non-OCP-violating geminates vs. OCP-violating singletons (non-initial); Contrast III=Two positions of singleton consonants.

\begin{tabular}{lll} 
& lower & upper \\
\hline General analysis & & \\
\hline OCP & 1.2615 & 1.5399 \\
Gem & 2.1313 & 2.3496 \\
Place & 0.0265 & 0.1676 \\
Frequency & 0.0001 & 0.0002 \\
\hline Contrast I & & \\
\hline OCP & 1.345 & 1.649 \\
\hline Contrast II & & \\
\hline Gem vs. sing & 1.389 & 1.662 \\
\hline Contrast III & & \\
\hline Initiality & -0.4296 & -0.2329 \\
\hline
\end{tabular}

\subsection{Place effects}

Turning to the effects of place on the devoicing of OCP-violating geminates, Figure 2 illustrates average ratings in the four conditions. A linear mixed model analysis did not reveal a significant effect of place on the naturalness rating of OCP-violating geminates $(t=0.317, n . s$.; the average ratings: $[\mathrm{bb}]=3.31 ;[\mathrm{dd}]=4.01 ;[g g]=3.82){ }^{6}$ For non-OCP-violating geminates, backer consonants tended to receive higher ratings, although the effect of place did not reach significance in this condition either $(t=0.91$, n.s.; the average ratings: $[\mathrm{b}]=2.28 ;[\mathrm{d}]=2.44 ;[\mathrm{g}]=2.48)$. No consistent place effects were observed in initial singletons $(t=0.90$, n.s.; the average ratings: $[\mathrm{bb}]=1.40$; $[\mathrm{dd}]=1.34 ;[\mathrm{gg}]=1.52)$ or in non-initial singletons $(t=1.28$, n.s.; the average ratings: $[\mathrm{bb}]=1.50$; $[\mathrm{dd}]=2.10 ;[\mathrm{gg}]=1.80)$.

\footnotetext{
${ }^{6}$ A question arises as to where the difference between this result and Nishimura's (2003) result comes from. According to Nishimura's (2003) data, [gg] is more likely to devoice than [dd] (Kawahara, 2006), whereas in this experiment speakers rated devoicing of [dd] more natural than devoicing of [gg] (although the difference did not reach significance). This discrepancy calls for a systematic comparison between judgment data and corpus data. See Kawahara (2010) — a follow-up study of the current experiment—for relevant discussion.
} 


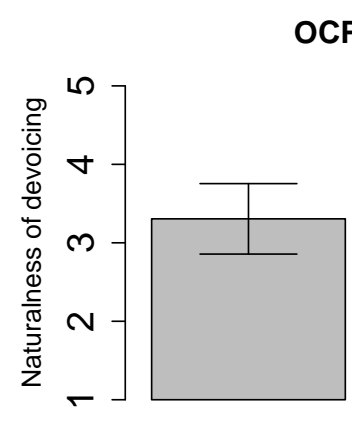

$\mathrm{bb}$

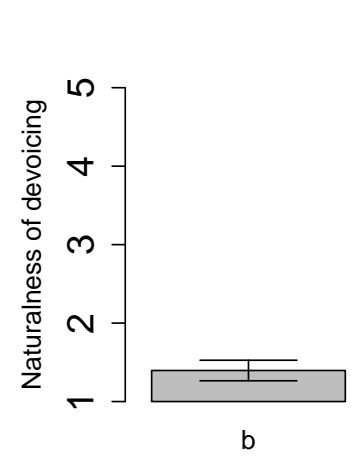

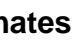

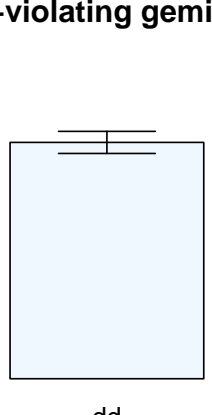

dd

Initial singletons

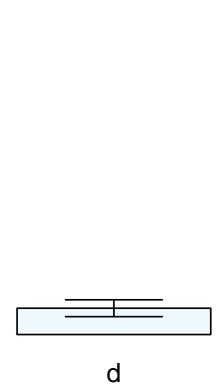

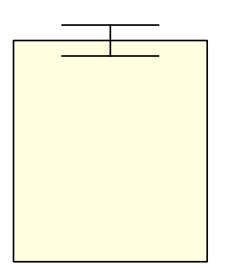

gg

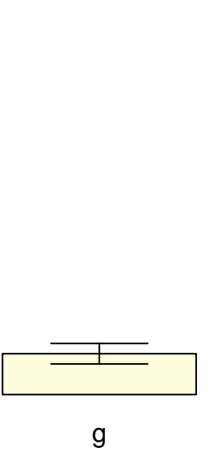

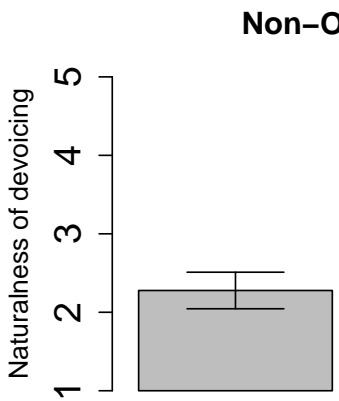

bb

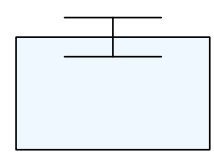

dd

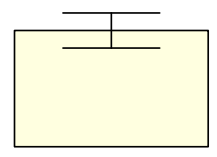

gg

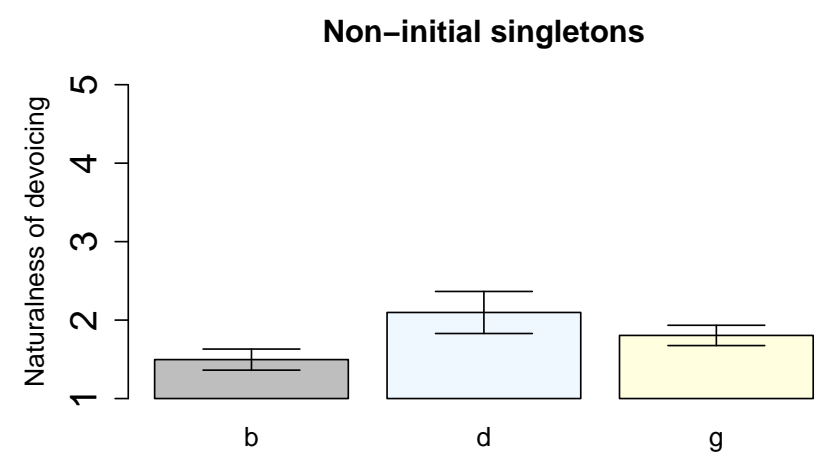

Figure 2: The effects of place on devoicing in the four conditions. 
An anonymous reviewer pointed out that even though the effect of place was not significant in these analyses, labials generally received lower scores than coronals and dorsals. The reviewer further pointed out that the current stimuli contained only one item with geminate [bb] in the OCP-violating geminate condition (see Table 1). The question therefore arises whether the high rating of devoicing of OCP-violating geminates is due to the fact that the OCP-violating geminate condition contained only one item with [bb]. To address this question, a linear-mixed model was rerun excluding all labial stimuli, and still revealed significant differences between OCP-violating geminates and non-OCP-violating geminates $(t=16.07, p<.001)$.

\subsection{Lexical frequency effects}

Next, Figure 3 illustrates the correlation between the average ratings and the natural log-frequencies in all four conditions $(\ln (0)$ was replaced with 0$)$. Spearman correlation tests reveal a statistically significant correlation between the lexical frequency of words and the corresponding naturalness rating in OCP-violating geminates $(\rho=.19, p<.001)$ and in non-initial singletons $(\rho=.17, p<.001)$. In these conditions, high frequency-words show tendency toward higher rating. The correlation was not significant in non-OCP-violating geminates $(\rho=.1, n . s$.$) and in$ initial singletons $(\rho=-.09, n . s$.). These analyses show that frequency affects rating only in some grammatical conditions, including OCP-violating geminates.

\subsection{Post-hoc, item-specific analyses}

Now I turn to discussion of items that have certain properties. ${ }^{7}$ To assess each post-hoc analysis, linear mixed models with speakers and items as random factors were used. To soak up variability as much as possible, other fixed factors were included where possible. Since there were four repeated post-hoc analyses, to avoid inflation of Type I error, the alpha level was adjusted to $.05 / 4=.0125$ by Bonferronization.

\subsubsection{Non-local OCP}

Within items that contain OCP-violating geminates, two items have long-distance triggers: [doreddo] 'dread' and [doraggu] 'drug'. Since dissimilatory force is cross-linguistically known to be stronger between two closer elements (Frisch et al., 2004; Suzuki, 1998), one may expect that devoicing of these two words may be considered to be less natural. In fact, Vance (1980) shows in his nonceword experiment that the blockage of Rendaku due to OCP(voice) (see footnote 1) is more likely when the trigger is closer.

\footnotetext{
${ }^{7}$ Thanks to an anonymous reviewer who pointed out that these post-hoc analyses may be informative.
} 

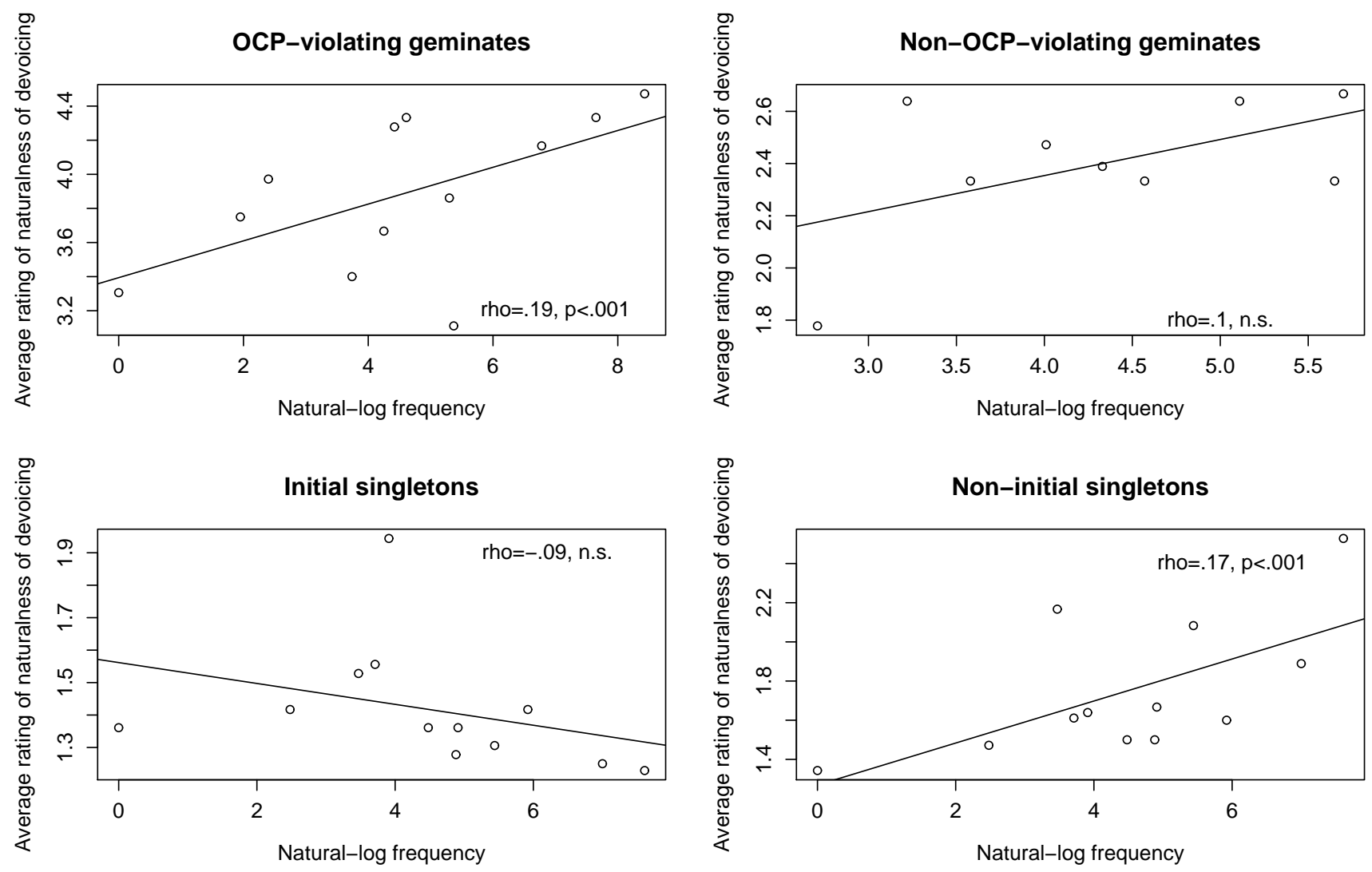

Figure 3: The correlation between the average rating of devoicing and the natural log-frequencies of the items for each condition. X-axies and Y-axies are on different scales in each graph. 
A post-hoc linear mixed model with locality of OCP-violation, together with frequency and place, as fixed independent factors was run between the two items with long-distance OCP-triggers and the rest of the items. Although we find a trend in which the two items containing long-distance trigger received lower rating (3.43) than the others (3.98), the difference did not reach significance $(t=1.51, n . s$.$) .$

\subsubsection{Double triggers}

Second, in the OCP-violating geminate condition, there are two items that contain two triggers for OCP(voice): [deddobooru] 'deadball' and [deibiddo] 'David'. As Tesar (2007) points out, devoicing geminates in such words would still entail a configuration that violates OCP(voice): [dettobooru] and [deibitto]. Kawahara (2008) and Tesar (2007) suggest that OCP(voice) can militate against each pair of OCP-violating voiced consonants so that devoicing of geminates would still lessen the violation of $\mathrm{OCP}$ (voice). Nevertheless, it may be possible that devoicing of these geminates can be considered less natural than others because devoicing does not resolve OCP(voice) violations completely.

Although the speakers rated the two items with double triggers lower (3.84) than the other items (4.13), a linear-mixed model with the number of triggers (together with frequency and place) as fixed factors did not reveal a significant difference between the two groups $(t=1.48, n . s$.).

\subsubsection{Merger with existing words}

Some items containing OCP-violating geminates merge with some existing lexical items: [baddo] 'bad' vs. [batto] 'bat', [baggu] 'bag' vs. [bakku] 'back' and [doggu] 'dog' vs. [dokku] 'dock'. Some scholars point out that languages may avoid mergers of two existing lexical items (Blevins, 2005; Ichimura, 2006) (see also general anti-merger constraints within the framework of Dispersion Theory: Flemming 1995; Itô \& Mester 2004; Padgett 2002; Urbanczyk 2005).

A linear mixed model with the possibility of merger, place and frequency within the OCPviolating geminate condition did not reveal a significant difference between those that result in merger and those that do not (3.80 vs. 3.91; $t=-0.51, n . s$.$) , although those that do not result in$ merger showed slightly higher ratings.

\subsubsection{Devoiceability of the following vowel}

Finally, devoiceability of the vowels following the target consonants may affect the naturalness rating of devoicing for the following reason. Devoicing of consonants may create an environment for high vowel devoicing in Japanese, which takes place between two voiceless consonants and word-finally after voiceless consonants (e.g. Tsuchida 1997). Speakers may disprefer devoicing of 
voiced consonants that will feed high vowel devoicing, because the devoicing of consonants would yield further unfaithful—or more dissimilar_forms with respect to the original forms.

The stimuli that contain OCP-violating geminates were thus categorized into two groups: one in which devoicing of the target consonants can yield high vowel devoicing and those that cannot. A general linear mixed model with place, frequency, and devoiceability of the following vowel shows that the effect of devoiceability of the following vowel did not influence the rating of OCP-violating geminates (those followed by devoiceable vowels: 3.92 vs. those followed by non-devoiceable vowels: $3.82 ; t=-0.56, n . s$.$) .$

\subsubsection{Summary of post-hoc analyses}

The first three post-hoc analyses showed interesting trends in directions that we expect from theoretical considerations, although none of the effects turned out to be significant. We should bear in mind, however, that these results are based on post-hoc analyses. Therefore, the devoicing of OCPviolating geminates may provide a testing ground for addressing these theoretical considerations in future research (Kawahara, 2010).

\section{Discussion}

\subsection{Summary}

To summarize the results, the current experiment confirms the intuition-based data of Nishimura (2003) and Kawahara (2006) in that Japanese speakers find the devoicing of OCP-violating geminates most natural. In this respect, the current work has succeeded in securing the empirical foundations of the theoretical claims reviewed in section $1.1 .^{8}$

\subsection{Gradiency: Beyond a grammatical/ungrammatical dichotomy}

In addition to confirming the naturalness of devoicing of OCP-violating geminates, the current experiment makes two findings beyond what Nishimura (2003) and Kawahara (2006) report. First, it found a positive correlation between the naturalness of the devoicing of OCP-violating geminates and the lexical frequencies of the items under question. Interestingly, the correlation was only significant under certain grammatical conditions (OCP-violating geminates and non-initial singletons).

\footnotetext{
${ }^{8}$ One remaining question is whether the judgement pattern reflects the frequencies of devoicing of voiced consonants in Japanese loanword phonology. Unfortunately, Amano and Kondo (2000), being a written database, does not contain many forms that undergo devoicing. A production experiment would be able to fill the gap-see section 4.3 .
} 
Second, the experiment revealed further distinctions among those devoicing patterns that were judged to be ungrammatical by Nishimura (2003) and Kawahara (2006): Japanese speakers find the devoicing of non-OCP-violating geminates more natural than the devoicing of OCP-violating singletons; they also find the devoicing of singletons more natural in medial position than in initial position.

The fact that Japanese speakers found the devoicing of non-OCP-violating geminates more natural than the devoicing of OCP-violating singletons is interesting, because both structures are illicit in the native phonology and both are licit in the loanword phonology (Itô \& Mester, 1995, 1999). This difference could arise from the difference in perceptibility of a voicing contrast between singletons and geminates. Kawahara (2006) has demonstrated that a voicing contrast is perceptually less salient in geminates than in singletons; therefore speakers may prefer the devoicing of geminates in general to the devoicing of singletons. Alternatively, one could argue that voiced geminates are more marked than OCP-violating singletons.

The second new finding - that speakers find devoicing of singletons more natural in non-wordinitial positions than in word-initial positions-is also interesting, because in modern Japanese voiced stops are allowed in both word-initial and word-internal positions. The dispreference against devoicing of word-initial singletons may have its roots in the psycholinguistic prominence of initial positions (Hawkins \& Cutler, 1988; Horowitz et al., 1969, 1968; Nooteboom, 1981); since word-initial position plays an important role in lexical access, speakers disprefer changing segments in this position (Beckman, 1997; Kawahara \& Shinohara, 2010). ${ }^{9}$

More generally, the results show that, in line with other recent studies, grammatical intuitions are gradient (e.g., Chomsky 1965; Cohn 2006; Coetzee 2008, 2009; Coleman \& Pierrehumbert 1997; Fanselow et al. 2006; Frisch et al. 2000, 2004; Greenberg \& Jenkins 1964; Hay et al. 2003; Hayes 2000, 2009; Hayes \& Londe 2006; Myers 2009; Pierrehumbert 2001; Schütze 1996; Zuraw 2000) in the following two senses. First, it is not the case that some devoicing patterns are grammatical and some other devoicing patterns are ungrammatical. Each factor (geminacy, OCP, wordposition) affects the naturalness of devoicing. Second, lexical frequencies gradiently affect the naturalness of devoicing of geminates, showing that distinctions exist even among OCP-violating geminates.

One general lesson we can draw from the results is that it may be dangerous to rely on an intuition-based dichotomous distinction between "grammatical" and "ungrammatical" processes, as was assumed by Nishimura (2003) and Kawahara (2006). The current results show that our linguistic knowledge provides much more fine-grained distinctions; speakers can tell the difference between three "ungrammatical devoicing patterns" (i.e. devoicing of non-OCP-violating geminates

\footnotetext{
${ }^{9}$ There are languages which avoid initial voiced stops, such as Old Japanese (Hamano, 2000; Vance, 1980), as it is articulatorily challenging to initiate voicing in word-initial position (Westbury \& Keating, 1986). Thus, from an articulatory point of view, one would expect that speakers would prefer devoicing of word-initial voiced stops.
} 
and devoicing of singletons in two positions).

I acknowledge that there is a view that grammar itself is categorical and apparent gradient patterns arise from extra-grammatical factors (Sprouse, 2007) (see also Schütze 1996 for extensive discussion). In this view, grammar could consider devoicing of OCP-violating geminates grammatical and the other three types of devoicing ungrammatical (as Nishimura 2003 and Kawahara $2006 \mathrm{did}$ ), and some "extra-grammatical factors" could be responsible for yielding the differences between the latter three types of devoicing. For example, these further distinctions could arise from the fact that the scale provided was gradient: the participants were somehow forced to as-

sume that they needed to make a full use of the scale provided. However, in this view, where to draw the line between "grammatical" and "ungrammatical" can become arbitrary. One follow-up experiment that could address the grammar-as-always-binary view is to use a binary forced-choice experiment, although this paradigm may coerce an unnatural binary distinction when the actual grammatical distinctions are finer than binary.

\subsection{Topics for future experimentation}

Finally, this paper opens up (at least) three lines of future research. First, the current experiment used real words for two reasons: (i) in order to test the words that were used by Nishimura (2003) and Kawahara (2006) and (ii) in order to test the effect of lexical frequencies on devoiceability of OCP-violating geminates. However, in order to test the productivity of the devoicing, it would be worthwhile to run a similar experiment with nonce words.

Second, this experiment used visual stimuli rather than auditory stimuli. However, recall that one explanation for why only geminates can devoice under the duress of $\mathrm{OCP}($ voice) is because a voicing contrast is less perceptible in geminates than in singletons (Kawahara, 2006, 2008; Steriade, 2004). This explanation relies on a general principle that the less perceptible the phonological change is, the more it is tolerated by speakers (Steriade, 2001/2008). An auditory judgment experiment would be better suited for testing this specific hypothesis.

Third, it would be interesting to see if the patterns obtained in the current experiment can be systematically replicated in a production study in which speakers actually produce the relevant sounds. In this paradigm, one would need to avoid hyperarticulation of the stimuli by the speakers, which often happens in a laboratory setting. Moreover, visual presentation of the stimuli with explicit indication of voicing in orthography may discourage devoicing of the consonants under investigation. One promising strategy to overcome these potential difficulties is to have speakers engage in a conversation using some key words, which contain the target words of our interest. 


\subsection{Overall summary}

To summarize, many theoretical proposals have been made using the devoicing of OCP-violating geminates in Japanese. This paper succeeded in verifying the empirical foundation of such theoretical claims. However, the current experiment also revealed additional interesting aspects of devoicing patterns in Japanese. The current experiment thus contributes to a growing body of work that shows the importance of experimental verification of linguistic data, beyond-and in tandem with—a traditional approach using intuition-based data.

\section{Acknowledgements}

Thanks to Ikue Motoyanagi and Kazuko Shinohara for their help in getting many participants for the online test. For comments on previous versions of the paper, I am grateful to Aaron Braver, Maria Gouskova, Kyoko Yamaguchi, the members of Rutgers Experimental Group, including Asya Achimova, Vandana Bajaj, Justyna Grudzinska, Julien Musolino, Marta Suarez, and Kristen Syrett. My particular thanks go to the research assistants of the Rutgers phonetics lab in 2009-2010: Kelly Garvey, Lara Greenberg, Sophia Kao, and Shanna Lichtman. Comments and suggestions from three NLLT reviewers and Junko Itô also improved the content and the style of the present paper. The research is supported by a Research Council Grant from Rutgers University. All remaining errors are mine.

\section{References}

Alderete, John \& Alexei Kochetov (2009) Japanese mimetic palatalization revisited: Implications for conflicting directionality. Phonology 26(3): 369-388.

Amano, Shigeaki \& Tadahisa Kondo (2000) NTT database series: Lexical properties of Japanese, 2nd release. Tokyo: Sanseido.

Baayen, Harald R. (2008) Analyzing linguistic data: A practical introduction to statistics using R. Cambridge: Cambridge University Press.

Baayen, Harald R. (2009) LanguageR. R package.

Baayen, Harald R., D.J. Davidson, \& D. M. Bates (2008) Mixed-effects modeling with crossed random effects for subjects and items. Journal of Memory and Language 59: 390-412.

Batchelder, Eleanor Olds (1999) Rule or rote? Native-speaker knowledge of Japanese verb inflection. Proceedings of the Second International Conference on Cognitive Science .

Bates, D. M. (2005) Fitting linear mixed models in R. R News 5: 27-30.

Bates, D. M. \& D. Sarkar (2007) lme4: Linear mixed-effects models using S4 classes. R package. 
Beckman, Jill (1997) Positional faithfulness, positional neutralization, and Shona vowel harmony. Phonology 14(1): 1-46.

Berko, Jean (1958) The child's learning of English morphology. Word 14: 150-177.

Blevins, Juliette (2005) Understanding antigemination: Natural or unnatural history. In Linguistic diversity and language theories, Zygmunt Frajzyngier, David Rood, \& Adam Hodges, eds., Amsterdam: Benjamins, 203-234.

Bybee, Joan (1999) Usage-based phonology. In Functionalism and Formalism in Linguistics, Michael Darnell, Edith Moravscik, Michael Noonan, Frederick Newmeyer, \& Kathleen Wheatly, eds., Amsterdam: Benjamins, 211-242.

Bybee, Joan (2001) Phonology and Language Use. Cambridge: Cambridge University Press.

Chomsky, Noam (1965) Aspects of the Theory of Syntax. Cambridge: MIT Press.

Coetzee, Andries W. (2008) Grammaticality and ungrammaticality in phonology. Language 84(2): $218-257$.

Coetzee, Andries W. (2009) Grammar is both categorical and gradient. In Phonological Argumentation: Essays on Evidence and Motivation, Steve Parker, ed., London: Equinox, 9-42.

Coetzee, Andries W. \& Joe Pater (to appear) The place of variation in phonological theory. In The Handbook of Phonological Theory, 2nd Edition, John A. Goldsmith, Jason Riggle, \& Alan Yu, eds., Cambridge: Blackwell-Wiley.

Cohn, Abigail (2006) Is there gradient phonology? In Gradience in Grammar: Generative Perspectives, Gisbert Fanselow, Caroline Fery, Matthias Schlesewsky, \& Ralf Vogel, eds., Oxford: Oxford University Press, 25-44.

Coleman, John \& Janet Pierrehumbert (1997) Stochastic phonological grammars and acceptability. Computational Phonology : 49-56.

Cowart, Wayne (1997) Experimental syntax: Applying objective methods to sentence judgments. London: Sage Publications.

Crawford, J. Clifford (2009) Adaptation and transmission in Japanese loanword phonology. Doctoral dissertation, Cornell University.

Dabrowska, Ewa (2010) Naive vs. expert intuitions: An empirical study of acceptability judgments. The Linguistic Review 27(1): 1-23.

Davis, Stuart \& Natsuko Tsujimura (1991) An autosegmental account of Japanese verbal conjugation. Journal of Japanese Linguistics 13: 117-44.

Ernestus, Mirjam \& Harald R. Baayen (2003) Predicting the unpredictable: Interpreting neutralized segments in Dutch. Language 79: 5-38.

Fanselow, Gisbert, Caroline Féry, Ralf Vogel, \& Matthias Schlesewsky, eds. (2006) Gradience in Grammar: Generative Perspectives. Oxford: Oxford University Press.

Farris-Trimble, Ashley (2008) Cumulative faithfulness effects in phonology. Doctoral dissertation, 
Indiana University.

Flemming, Edward (1995) Auditory Representations in Phonology. Doctoral dissertation, University of California Los Angeles.

Frisch, Stefan, Nathan Large, \& David Pisoni (2000) Perception of wordlikiness: Effects of segment probability and length of the processing of nonwords. Journal of Memory and Language 42: 481-496.

Frisch, Stephan, Janet Pierrehumbert, \& Michael Broe (2004) Similarity avoidance and the OCP. Natural Language and Linguistic Theory 22: 179-228.

Gibson, Edward \& Evelina Fedorenko (2010) Weak quantitative standards in linguistics research. Trends in Cognitive Sciences 14(6): 233-234.

Greenberg, Joseph \& James Jenkins (1964) Studies in the psychological correlates of the sound system of American English. Word 20: 157-177.

Griner, Barry (2001) Productivity of Japanese verb tense inflection: A case study. MA thesis, University of California Los Angeles.

Hamano, Shoko (1986) The Sound-Symbolic System of Japanese. Doctoral dissertation, University of Florida, [Published by CSLI Publications, Stanford 1998].

Hamano, Shoko (2000) Voicing of obstruents in Old Japanese: Evidence from the sound-symbolic stratum. Journal of East Asian Linguistics 9: 207-215.

Haraguchi, Shosuke (2006) A theory of voicing. Ms. Meikai University (available at http://www.let.leidenuniv.nl/ulcl/faculty/vdweijer/jvoice/haraguchi.pdf).

Hawkins, John \& Anne Cutler (1988) Psycholinguistic factors in morphological asymmetry. In Explaining Language Universals., J. A. Hawkins, ed., Oxford: Basil Blackwell, 280-317.

Hay, Jennifer, Janet Pierrehumbert, \& Mary Beckman (2003) Speech perception, well-formedness, and the statistics of the lexicon. In Papers in Laboratory Phonology VI: Phonetic interpretation, John Local, Richard Ogden, \& Rosalind Temple, eds., Cambridge: Cambridge University Press, $58-74$.

Hayes, Bruce (2000) Gradient well-formedness in Optimality Theory. In Optimality Theory: Phonology, Syntax, and Acquisition, Joost Dekkers, Frank Van der Leeuw, \& Jeroen Van de Weijer, eds., Oxford: Oxford University Press, 88-120.

Hayes, Bruce (2009) Embedding grammar in a quantitative framework: Case Studies from phonology and metrics. A handout for a minicourse at Brown University.

Hayes, Bruce \& Zsuzsa Londe (2006) Stochastic phonological knowledge: The case of Hungarian vowel harmony. Phonology 23: 59-104.

Horowitz, Leonard, Peter Chilian, \& Kenneth Dunnigan (1969) Word fragments and their reintegrative powers. Journal of Experimental Psychology 80(2): 392-394.

Horowitz, Leonard, Margeret White, \& Douglas Atwood (1968) Word fragments as aids to recall: 
The organization of a word. Journal of Experimental Psychology 76(2): 219-226.

Ichimura, Larry (2006) Anti-homophony Blocking and Its Productivity in Transparadigmatic Relations. Doctoral dissertation, Boston University.

Itô, Junko \& Armin Mester (1986) The phonology of voicing in Japanese: Theoretical consequences for morphological accessibility. Linguistic Inquiry 17: 49-73.

Itô, Junko \& Armin Mester (1995) Japanese phonology. In The Handbook of Phonological Theory, John Goldsmith, ed., Oxford: Blackwell, 817-838.

Itô, Junko \& Armin Mester (1999) The phonological lexicon. In The Handbook of Japanese Linguistics, Natsuko Tsujimura, ed., Oxford: Blackwell, 62-100.

Itô, Junko \& Armin Mester (2004) Morphological contrast and merger: Ranuki in Japanese. Journal of Japanese Linguistics 20: 1-19.

Itô, Junko \& Armin Mester (2008) Lexical classes in phonology. In The Oxford Handbook of Japanese Linguistics, S. Miyagawa \& M. Saito, eds., Oxford: Oxford University Press, 84-106. Jaeger, Jeri J. (1983) Assessing the psychological status of the Vowel Shift Rule. Journal of Psycholinguistic Research 13: 13-36.

Kaneko, Emiko \& Gregory Iverson (2009) Phonetic and other factors in Japanese on-line adaptation of English final consonants. In Studies in Language Sciences 8: Papers from the eighth annual conference of the Japanese Society for Language Science, Shunji Inagaki \& Makiko Hirakawa, eds., Tokyo: Kuroshio Publications.

Katayama, Motoko (1998) Optimality Theory and Japanese Loanword Phonology. Doctoral dissertation, University of California at Santa Cruz.

Kawahara, Shigeto (2006) A faithfulness ranking projected from a perceptibility scale: The case of voicing in Japanese. Language 82(3): 536-574.

Kawahara, Shigeto (2008) Phonetic naturalness and unnaturalness in Japanese loanword phonology. Journal of East Asian Linguistics 18(4): 317-330.

Kawahara, Shigeto (2010) Aspects of Japanese loanword devoicing. Ms. Rutgers University (submitted for publication in Journal of East Asian Linguistics).

Kawahara, Shigeto (2011) Experimental approaches in theoretical phonology. In The Blackwell companion to phonology, Marc van Oostendorp, Colin J. Ewen, Elizabeth Hume, \& Keren Rice, eds., Oxford: Blackwell-Wiley.

Kawahara, Shigeto \& Kazuko Shinohara (2010) Phonetic and psycholinguistic prominences in pun formation: Experimental evidence for positional faithfulness. In Japanese/Korean Linguistics 18, W. McClure \& M. den Dikken, eds., Stanford: CSLI, 177-188.

Lovins, Julie (1973) Loanwords and the Phonological Structure. Doctoral dissertation, University of Chicago, distributed by IULC Publications 1975.

Lyman, Benjamin S. (1894) Change from surd to sonant in Japanese compounds. Oriental Studies 
of the Oriental Club of Philadelphia : 1-17.

McCarthy, John J. (2008) Doing Optimality Theory. Oxford: Blackwell-Wiley.

Mester, Armin \& Junko Itô (1989) Feature predictability and underspecification: Palatal prosody in Japanese mimetics. Language 65: 258-93.

Myers, James (2009) Syntactic judgment experiments. Language and Linguistic Compass 3(1): 406-423.

Nishimura, Kohei (2003) Lyman's Law in loanwords. MA thesis, Nagoya University.

Nolan, Francis (1992) The descriptive role of segments: Evidence from assimilation. In Papers in Laboratory Phonology II: Gesture, Segment, Prosody, G. R. Docherty \& D. R. Ladd, eds., Cambridge: Cambridge University Press, 261-280.

Nooteboom, Sieb (1981) Lexical retrieval from fragments of spoken words: Beginnings vs. endings. Journal of Phonetics 9: 407-424.

Ohala, John J. (1974) Experimental historical phonology. In Historical Linguistics II: Theory and Description in Phonology. Proceedings of the First International Linguistic Conference on Historical Linguistics, J. M. Naderson \& Charles Jones, eds., New York: Elsevier, 353-389.

Padgett, Jaye (2002) Contrast and postvelar fronting in Russian. Natural Language and Linguistic Theory 21: 39-87.

Pater, Joe (2009) Weighted constraints in generative linguistics. Cognitive Science 33: 999-1035.

Pertz, D. L. \& T. G. Bever (1975) Sensitivity to phonological universals in children and adolescents. Language 51: 149-162.

Pierrehumbert, Janet B. (2001) Stochastic phonology. GLOT 5: 1-13.

Prince, Alan \& Paul Smolensky (1993/2004) Optimality Theory: Constraint Interaction in Generative Grammar. Malden and Oxford: Blackwell.

Pycha, Anne, Eurie Shin, \& Rhan Shosted (2006) Directionality of assimilation in consonant clusters: An experimental approach. UC Berkeley Phonology Lab Annual Report : 152-166.

R Development Core Team (1993-2010) R: A language and environment for statistical computing. R Foundation for Statistical Computing, Vienna, Austria.

Reips, Ulf-Dietrich (2002) Standards for internet-based experimenting. Experimental psychology 49(4): 243-256.

Rice, Keren (2006) On the patterning of voiced stops in loanwords in Japanese. Toronto Working Papers in Linguistics 26: 11-22.

Sanders, Nathan (2003) Opacity and Sound Change in the Polish Lexicon. Doctoral dissertation, University of California, Santa Cruz.

Schütze, Carlson (1996) The empirical base of linguistics: Grammaticality judgments and linguistic methodology. Chicago: University of Chicago Press.

Shinohara, Shigeko (2004) Emergence of Universal Grammar in foreign word adaptations. In Con- 
straints in Phonological Acquisition, René Kager, Joe Pater, \& Wim Zonneveld, eds., Cambridge: Cambridge University Press, 292-320.

Shirai, Setsuko (2002) Gemination in Loans from English to Japanese. MA thesis, University of Washington.

Sprouse, Jon (2007) Continuous acceptability, categorical grammaticality, and experimental syntax. Biolinguistics 1: 118-129.

Steriade, Donca (2001/2008) The phonology of perceptibility effects: The P-map and its consequences for constraint organization. In The nature of the word, Kristin Hanson \& Sharon Inkelas, eds., Cambridge: MIT Press, 151-179, originally circulated in 2001.

Steriade, Donca (2004) Projecting non-lexical phonology from phonetic knowledge. A talk presented at "Symposium on phonological theory: representations and architectures" (the City University of New York, Feb 20-21st, 2004).

Suzuki, Keiichiro (1998) A Typological Investigation of Dissimilation. Doctoral dissertation, University of Arizona.

Tanaka, Shin-Ichi (2010) The eurhythmics of segmental melody. Journal of the Phonetic Society of Japan 13(3): 44-52.

Tateishi, Koichi (2002) Bunpoo no ichibutoshite no goisoo no zehi [Lexical strata as a part of grammar]. Journal of the Phonetic Society of Japan 6(1): 34-43.

Tesar, Bruce (2007) A comparison of lexicographic and linear numeric optimization using violation difference ratios. Ms. Rutgers University.

Tsuchida, Ayako (1997) Phonetics and Phonology of Japanese Vowel Devoicing. Doctoral dissertation, University of Cornell.

Urbanczyk, Suzanne (2005) Enhancing contrast in reduplication. In Studies on reduplication, B. Hurch, ed., Mouton: de Gruyter, 431-454.

Vance, Timothy J. (1980) The psychological status of a constraint on Japanese consonant alternation. Linguistics 18: 245-267.

Vance, Timothy J. (1987) An Introduction to Japanese Phonology. New York: SUNY Press.

Westbury, J. R. \& Patricia Keating (1986) On the naturalness of stop consonant voicing. Journal of Linguistics 22: 145-166.

Zuraw, Kie (2000) Patterned Exceptions in Phonology. Doctoral dissertation, University of California, Los Angeles.

Zuraw, Kie (2009) Frequency influences on rule application within and across words. In Proceedings of Chicago Linguistic Society 43-2, Chicago Linguistics Society, 283-309. 